\section{Non-painful severe variant form of eruptive lingual papilli- tis: A case report and literature review}

\author{
Manal Ahmed Halwani \\ Department of Emergency Medicine, \\ Division of Pediatric Emergency, \\ Faculty of Medicine, King Abdulaziz \\ University, Jeddah, Saudi Arabia
}

condition. ${ }^{7}$ The associated symptoms are fever, extensive salivation, burning sensation, and adenopathy. ${ }^{8}$ Though lingual papillitis has been described in several scientific literature, its clinical expressions are yet to be fully elucidated. ${ }^{9}$ In this paper, a case report of non-painful severe variant form of eruptive lingual papillitis is presented. The cause was idiopathic and the symptoms were resolved within 10 days. This report is to provide an insight into the previously unreported case of non-painful severe variant form of eruptive lingual papillitis along with its diagnosis and management.

\begin{abstract}
Eruptive lingual papillitis is a common benign disorder manifested by inflammation of fungiform papillae on the dorsolateral surface of the tongue. Several variants of lingual papillitis have been reported since 1997 , most or all of them with painful erythematous papules. Here we report a case of 6 years old girl child with non-painful severe variant form of eruptive lingual papillitis presented to the emergency department. The entire dorsal surface of the tongue was surfaced by $2-3 \mathrm{~mm}$ by multiple erythematous papules and some with a white or yellowish colour. The papules were excessively inflamed, pigmented, aggregated, and crusted. The cause was idiopathic which resolved within ten days. The parent and patient were reassured with advice to practice oral hygiene. This is a rare case report describing non-painful lingual papillitis without a history of any prior episodes.
\end{abstract}

\section{Introduction}

Eruptive lingual papillitis is acute stomatitis without any known causative factor, generally affecting children. Although no confirmed etiology is known, some scientific literature attributed it to viral infections, stress, trauma, food hypersensitivity, and atopic disease. ${ }^{1-3}$ ELP has been described as eruptive familial lingual papillitis' owing to its transmission from affected individuals to other family members. ${ }^{4}$ ELP is manifested by inflammatory swollen blisters (papules), trouble in feeding, and irritability. ${ }^{5}$ Inflammation of fungiform papillae is characterized by acute onset, with 2 to $3 \mathrm{~mm}$ multiple erythematous papules along with mild to extreme pain. ${ }^{3}$ The papules may be red or yellow/white and encompass fungiform papillae of lingual area, commonly at the tips, on lateral, and dorsal parts. 6 The hypertrophic fungiform papillae have been described as transient lingual papillitis (TLP) due to its transient nature and painful

\section{Case Report}

\section{Clinical presentation}

A 6-year-old female child presented to the emergency department with erythematous papules all over the tongue and with profuse salivation. According to her mother, it started as a sudden onset; this was her first time of this illness, she had difficulty in oral intake, no previous complaint, not known to have any medical illness or on any medication, no history of exposure to any detergent or household substances, no history of trauma, parafunctional habits or allergy. There was no history of fever, sore throat, or other respiratory symptoms.

Clinical examination revealed, multiple blood blisters of $2-3 \mathrm{~mm}$ all over the tongue including the edge and the dorsal part. Some of these are too swollen appearing pustular form. Hypertrophic fungiform papillae were prominent at the tip and anterior dorsal part of the tongue (Figure 1). Papillae were of erythematous to yellowishwhite in colour, some pigmented. They exhibit varied shapes, from round to deform. Clinically no vesicles, erosions, or oral thrush were observed. Tongue abnormalities such as geographic or fissured tongue were not found. No florid involvement was noticed. The lips, lingual gingivae, palate, and throat had a normal appearance. Some non-painful crusted blisters were noticed. A sign of herpetic stomatitis was lacking. Other examination showed palpable submental and submandibular non-tender lymph nodes.

Laboratory investigation was unremarkable.

\section{Diagnosis}

Based on clinical presentation the entity was diagnosed as non-painful severe variant form of eruptive lingual papillitis of idiopathic cause.
Correspondence: Manal Ahmed Halwani, Department of Emergency Medicine, Division of Pediatric Emergency, Faculty of Medicine, King Abdulaziz University, Jeddah 22252, Saudi Arabia.

Tel.: +966-50.553.0031

E-mail: mahalawani@kau.edu.sa

Key words: Eruptive lingual papillitis; nonpainful lesions; erythematous papules; topical oral antiseptic.

Conflict of interest: The author declares no potential conflict of interest.

Funding: None.

Ethics approval: Received.

Consent to publication: Received.

Please cite this article as: Halwani MA. Nonpainful severe variant form of eruptive lingual papillitis: A case report and literature review. Dermatol Rep 2021;13:9020.

Received for publication: 15 November 2020 Revision received: 11 January 2021

Accepted for publication: 12 January 2021 .

This work is licensed under a Creative Commons Attribution-NonCommercial 4.0 International License (CC BY-NC 4.0).

${ }^{\circ}$ Copyright: the Author(s), 2021

Licensee PAGEPress, Italy

Dermatology Reports 2021; 13:9020

doi:10.4081/dr.2021.9020

\section{Management}

The patient was advised to practice oral hygiene and follow-up was done after seven days, $80 \%$ of the lesions was resolved. Subsequent follow-up after three months showed no recurrent lesion.

\section{Discussion}

Eruptive lingual papillitis is the benign inflammation of fungiform papilla on the tip, lateral, and dorsal parts of the tongue. ${ }^{2}$ Detailed information on ELP in pediatric patient is also limited. Generally, it is manifested by acute onset of painful erythematous tender papules and few vesicles and crusted lesions. ${ }^{6}$ Fever, difficulty in feeding, burning sensation, salivation, and cervical adenopathy are usually associated. The lesions may be both localized or generalized and usually resolve between one to several days based on clinical presentation. $^{10}$

Although not well documented, ELP appears to be associated with viral infec- 
tions, allergens, emotional stress, anxiety, trauma, hormonal changes, atopic diseases, gastrointestinal upset, and food sensitivity. $2,7,11,12$ Earlier studies revealed the possibility of transmission from the affected person to other family members suggesting its infectious nature. ${ }^{5}$ It has been described that viral infections may be associated with eruptive glossitis, and its possible transmission from one to other family members, as in the case with eruptive familial lingual papillitis. ${ }^{4}$ Other studies described its transient nature and possibility for recurrence, attributed to transient lingual papillitis. ${ }^{5}$

Though the clinical feature of the present case is similar to most of the earlier reported manifestations, there are some differences like non-painful lesions, severe presentation, absence of fever, recurrences, and without the familial pattern of distribution. The lesions were transient and showed gradual regression within seven days and completely resolved in ten days. The finding was comparable to previously reported cases of transient lingual papillitis. ${ }^{10}$ Another striking observation in the present case was the absence of the occurrence of any previous episodes. Due to the above clinical manifestations, the present entity has been assigned as 'non-painful severe variant form of eruptive lingual papillitis', a transient variant of ELP.

Most of the treatments of ELP involve the use of topical corticosteroids, saline or chlorhexidine mouth wash, topical anesthetics, coating agents, antihistamine, and analgesics. ${ }^{13}$ In the present case reassuring the parent and advise to practice oral hygiene was found useful. Patients were advised not to take hot and spicy food to avoid irritability. Differential diagnosis includes scarlet fever (exhibition of strawberry or raspberry tongue due to hypertrophic fungiform papillae), erythematous candidiasis, and food allergy. ${ }^{14}$

A literature search in PubMed was performed using the term "eruptive lingual papillitis". An extensive search revealed only three reports that have been previously documented. The clinicopathological presentations, as well as of the present case are summarized in Table 1. All the cases had a similar clinical presentation of the painful hypertrophic lesion over the tongue, acute onset of the eruption, and salivation. Our case was unique and unreported previously, as manifested by non-painful lesions. In all the cases studied except the present, symptoms were identically manifested by pain and burning sensation. ${ }^{4,5,15}$ Most of the cases complained about difficulty during food intake. In one of the studies, cases with fever were reported. ${ }^{5}$ Earlier studies attributed ELP to either familial or viral etiology, which was found to be idiopathic in the present case. None of the earlier studies described non-painful erythematous papules over the tongue The clinical manifestations presented in this study were sufficient to suggest the present entity as distinct and unreported. Biopsy is not required for the final diagnosis. ${ }^{4}$ The pathologic findings seeing a condition we distinguish as a common papulokeratotic variation of transient lingual papillitis are shown already. ${ }^{10}$

\section{Conclusions}

This paper reported the clinical presentation of non-painful severe variant form of eruptive lingual papillitis of a 6 years old girl child. Based on the clinical manifestations the non-painful condition of ELP was unusual. Although diagnosis has been done based on the clinical presentation of the patient, further studies should be carried out to trace specific clinical diagnostic criteria of ELP. The factors responsible for triggering the symptoms must be further investigated to elucidate proper diagnosis.

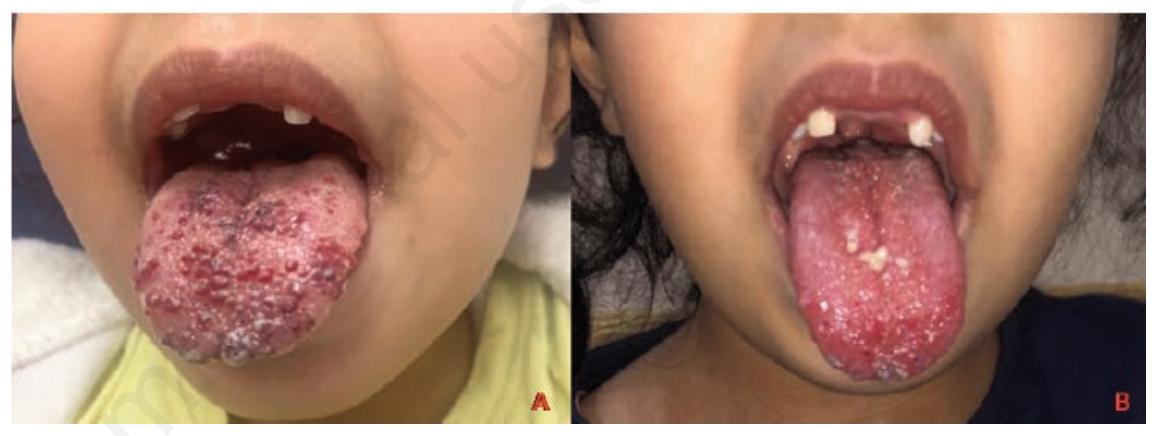

Figure 1. Multiple erythematous papules with swollen pseudopustules on the edge and dorsal part of the tongue at (A) initial screening (B) after 7 days.

Table 1. Summary of published reports on eruptive lingual papillitis.

\begin{tabular}{|c|c|c|c|c|c|c|c|}
\hline Etiology & Age & Gender & Duration & Clinical Presentation & Diagnosis & $\begin{array}{l}\text { Recurrence of } \\
\text { symptoms }\end{array}$ & References \\
\hline Familial & $\begin{array}{l}3 \text { months } \\
6 \\
7 \\
50 \\
10\end{array}$ & $\begin{array}{l}\text { Female } \\
\text { Male } \\
\text { Male } \\
\text { Male } \\
\text { Male }\end{array}$ & $\begin{array}{l}8-10 \text { days } \\
8 \text { days } \\
8 \text { days } \\
15 \text { days } \\
8 \text { days }\end{array}$ & $\begin{array}{l}\text { Abrupt onset of the eruption, } \\
\text { painful lesions of the papillae, } \\
\text { burning sensation }\end{array}$ & $\begin{array}{l}\text { Hypertrophic red papillae } \\
\text { on the anterior part } \\
\text { of her tongue }\end{array}$ & Reported & Lacour and Perrin [4] \\
\hline $\begin{array}{l}\text { Household } \\
\text { transmission }\end{array}$ & $\begin{array}{l}38 \text { children } \\
\text { mean age } \\
3 \text { years and } \\
6 \text { months } \\
\text { (range } 13 \\
0 \text { years) }\end{array}$ & $\begin{array}{l}21 \text { Female } \\
17 \text { Male }\end{array}$ & $\begin{array}{l}\text { Mean duration } \\
7.3 \text { days }\end{array}$ & $\begin{array}{l}\text { Abrupt onset of eruption with } \\
\text { and without fever, difficulties } \\
\text { in feeding, pain and burning } \\
\text { sensation, increased salivation, } \\
\text { and irritability }\end{array}$ & $\begin{array}{l}\text { Localized lesions on the tip and } \\
\text { dorsolateral part of the tongue, } \\
\text { high frequency of intrafamilial } \\
\text { transmission ( } 53 \%) \text {, } \\
\text { and the possibility of recurrence (13\%) }\end{array}$ & Reported & Roux and Lacour [5] \\
\hline Viral & 8 & Male & 10 days & $\begin{array}{l}\text { Painful erythematous papules } \\
\text { over the tongue and profuse } \\
\text { salivation }\end{array}$ & $\begin{array}{l}\text { Multiple erythematous papules and few } \\
\text { vesicles over the tongue }\end{array}$ & Not-reported & Mondal and Kumar [15] \\
\hline Idiopathic & 6 & Female & 5 days & $\begin{array}{l}\text { Abrupt onset, non-painful } \\
\text { erythematous papules over the } \\
\text { tongue with profuse salivation }\end{array}$ & Eruptive lingual papillitis & None & Present case \\
\hline
\end{tabular}




\section{References}

1. Giunta JL. Transient Lingual Papillitis: Case reports. J Massachusetts Dent Soc 2009;58:26-7.

2. Raji K, Renario J, Ogunmakin K. Goodness, gracious, great balls of fire: A case of transient lingual papillitis following consumption of an atomic fireball. Dermatol Online J 2016;22

3. Gobara N, Costa K, Santos CVED, et al. Transient Lingual Papillitis-Case Report. Oral Surg Oral Med Oral Pathol Oral Radiol Edontol 2020;1:e118.

4. Lacour JP, Perrin C. Eruptive familial lingual papillitis: a new entity? Pediatr Dermatol 1997;14:13-6.

5. Roux O, Lacour JP. Eruptive lingual papillitis with household transmission: a prospective clinical study. Paediat Dermatol 2004;150:299-303.

6. Kalogirou EM, Tosios KI, Nikitakis NG, et al. Transient lingual papillitis: A retrospective study of 11 cases and review of the literature. J Clin Exp Dent 2017;9:e157-162.

7. Whitaker SB, Krupa JJ III, Singh BB. Transient lingual papillitis. Oral Surg Oral Med Oral Pathol Oral Radiol 1996;82:441-5.

8. Milano A. Localized transient lingual papillitis. Eur J Pediat Dermatol 2017;27:245.

9. Kornerup IM, Paedo D, Senye M, Peters E. Transient lingual papillitis. Quintess Int 2016;47:871-5.

10. Brannon RB, Flaitz CM. Transient lingual papillitis: A papulokeratonic variant. Oral Surg Oral Med Oral Pathol
Oral Radiol Edontol 2003;96:187-91.

11. Conklin RJ, Blasberg B. Common inflammatory diseases of the mouth. Int J Dermatol 1991;30:323-35.

12. Flaitz CM, Chavarria C. Painful tongue lesions associated with a food allergy. Pediatr Dent 2001;23:506-7.

13. Patil P, Naikmasur VG, Nandimath K. transient lingual papillitis: An unusual clinical presentation. Indian J Stomatol 2013;4:64-5

14. Annette M. Oral health a study guide for medical students and physician. California Digital Library, University of California. Available from: https://escholarship.org/uc/item/5hp4m $9 \mathrm{c} 5$.

15. Mondal A, Kumar P. Eruptive lingual papillitis. Indian Pediatr 2014;51:243. 